ARTIGO

DOI: https://doi.org/10.22481/praxis.v15i31.4673

\title{
OS SUJEITOS DA EJA E DA EDUCAÇÃO SOCIAL: AS PESSOAS EM SITUAÇÃO DE VULNERABILIDADE SOCIAL
}

\author{
THE SUBJECTS OF THE EJA AND SOCIAL EDUCATION: PEOPLE IN SITUATIONS \\ OF SOCIAL VULNERABILITY
}

\section{LOS SUJETOS DE LA EJA Y EDUCACIÓN SOCIAL: PERSONAS EN SITUACIÓN DE VULNERABILIDAD SOCIAL}

\author{
Antonio Pereira \\ Universidade do Estado da Bahia - Brasil
}

\begin{abstract}
Resumo: O texto trata dos novos sujeitos da Educação de Jovem e Adulto (EJA) e da Educação Social (ES): as pessoas em situação de vulnerabilidade e desfiliamento social, identificando-as e, ao mesmo tempo, problematizando a situação social em que vivem à luz da sociologia de Robert Castel que analisa o quanto as metamorfoses da questão social complexificaram a dinâmica interna da exclusão social a ponto de fazer emergir novas categorias que explicam melhor o fenômeno da marginalidade, por exemplo, a integração, assistidos, vulnerabilidade e desfiliamento social. O interesse aqui é em afirmar que os jovens, adultos e velhos que estão em uma dessas situações, em particular as duas últimas, são sujeitos da EJA, ainda que ela não os assumam; diferentemente da Educação Social que, historicamente, se constituiu como uma educação encetada na pedagogia de Paulo Freire, portanto lutando pelo empoderamento dessas pessoas.
\end{abstract}

Palavras-chave: Sujeitos da EJA. Educação Social. Vulnerabilidade Social. Desfiliamento Social

\begin{abstract}
The text deals with new subjects of Youth and Adult Education (EJA) and Social Education (ES): people in vulnerable social and desfiliamento situation, identifying them and the same time questioning the social situation in which they live to light sociology of Robert Castel analyzing how the metamorphosis of the social question complexificaram the internal dynamics of social exclusion as to bring out new categories that best explain the phenomenon of marginalization, for example, integration, assisted vulnerability and social desfiliamento. The interest here is to affirm that young people, adults and old people who are in one of these situations, in particular the last two, are subjects of the EJA, even if they do not assume them; Differently from Social Education that, historically, was constituted as an education initiated in the pedagogy of Paulo Freire, therefore fighting for the empowerment of these people.
\end{abstract}

Keywords: Subjects EJA. Social education. Social vulnerability. Social desfiliamento.

Resumen: El texto trata de nuevos sujetos de la Educación de Jóvenes y Adultos (EJA) y Educación Social (ES): personas en situación social y desfiliamento vulnerables, identificándolos y al mismo tiempo cuestionar la situación social en la que viven a sociología luz de Robert Castel analizar cómo la metamorfosis de la cuestión social complexificaram la dinámica interna de la exclusión social como 
para llevar a cabo nuevas categorías que mejor explican el fenómeno de la marginación, por ejemplo, la integración, la vulnerabilidad asistida y desfiliamento social. El interés aquí es decir que los jóvenes, adultos y ancianos que se encuentran en una de estas situaciones, especialmente los dos últimos, son sujetos de la EJA, a pesar de que no se les tomó; a diferencia de la educación social que históricamente constituida como una educación iniciada en la pedagogía de Paulo Freire, luchando por lo tanto para la potenciación de estas personas.

Palabras clave: Los sujetos da EJA. La educación social. La vulnerabilidad social. Desfiliamento social.

\section{Introdução}

Os sujeitos da Educação de Jovens e Adultos (EJA), atualmente, são todos aqueles que não lograram êxito na educação básica quando criança e adolescente e, consequentemente, tiveram uma inserção no mundo social e do trabalho fragilizada, sendo que parte desse quantitativo adentrou em processos de extrema fragmentação da vida social a tal ponto, que muitos passaram da zona de vulnerabilidade para a de indigência. Essas pessoas foram propositalmente esquecidas nas parcas políticas de inserção e integração em EJA, porque eram ações para os menos excluídos e que, mesmos assim, não lograram o êxito pretendido pelo Estado brasileiro quanto à erradicação do analfabetismo entre a população adulta, a história da Educação de Adultos (EA) não nos deixa mentir (PAIVA, 1987).

A hipótese desse esquecimento proposital está na ideia de que os mais excluídos não eram reconhecidos pela EJA, como sendo também seus sujeitos de conhecimento e de (trans)formação, porque havia o entendimento de que, como se tratava de uma educação para todos que foram excluídos da escola regular, logo não teria sentido defender uma atuação política, financeira e pedagógica diferenciada a partir de outros tipos de exclusões, que não a da escola, mesmo que tais exclusões fossem aprofundadas e determinadas pelas oportunidades educacionais não garantidas pelo Estado. A EJA optou por um sujeito genérico - aquele que apenas foi expulso dos processos formativos da escola por diversos motivos, deixando a própria sorte outros que se encontravam em situação de extrema fragilidade pessoal e social.

Não há dúvida de que a exclusão escolar provoca outras, como a do mercado de trabalho, pela ausência de uma profissionalização ampla, que, inevitavelmente, leva o sujeito a atividades precarizadas, a subempregos e desempregos constantes, afetando sua inclusão social, familiar. Muitos desses sujeitos irão fazer parte do grande efetivo de pessoas indigentes com necessidades e carências de todo tipo, desde a de subsistência, passando pela de habitação, saúde, educação, dentre outros. Hoje, a defesa é por uma Educação de Adultos (EA), separada da Educação de Jovens (escolarização regular e diurna para o jovem em 
qualquer condição social), que assume todos os sujeitos excluídos da escola e aqueles que, na trajetória de vida, tenham adquirido outras exclusões por força também da ausência de uma escolarização na chamada idade adequada.

A Educação Social (ES), há muito tempo, já assume esses sujeitos em suas práticas ressocializadoras, referenciadas na pedagogia de Paulo Freire, buscando, de alguma forma, suprir demandas educativas deixadas pela EJA, mas sem a ideia de substituí-la; pelo contrário, qualquer prática ressocializadora só termina na escolarização, pois existe o entendimento político emancipador dessa educação de que a escolarização é conditio sine qua non para todo e qualquer sujeito em situação ou não de marginalidade. A defesa pela escolarização plena para todos (incluindo as pessoas marginalizadas) se deve ao fato de que a escola continua socialmente relevante, lugar de aquisição dos conhecimentos acumulados pela humanidade, portanto, o acesso a ela significa, consequentemente, inserção social, lugar sociabilidade e que expressa em si a educação formal, sendo mesmo a "[...] força educativa que tudo domina." (SAVIANI, 2009, p. 21).

Nesse aspecto, é que todas as práticas educativas ressocializadoras deve sempre intencionar a escolarização dos indivíduos, para isso, a parceria EJA e ES é fundamental para concretizar essa intenção, possibilitando a existência de uma educação escolarizada, mais humana e sensível à situação social dos que estão marginalizados, abandonados, invisíveis, mas que saltam aos nossos olhos em cada rua, beco, lugar, não lugar, situação desumana e que agora são reclassificados pela sociologia francesa, como: vulneráveis, desfiliados, atendidos socialmente, facilitando a identificação pela situação vivida (CASTEL, 1998, 1997, 2000).

Esses novos (ou não seriam antigos?) sujeitos estão classificados ainda pelos indicadores econômicos e sociais do Brasil, como os mais pobres da população com uma taxa de analfabetismo em torno de 15\% (BRASIL, 2010). E, embora pareça contraditório separar os mais pobres dos pobres, já que todos estão na mesma condição, para efeito de política pública é fundamental localizar os diversos grupos que compõem a grande exclusão social (CASTEL, 1997), mesmo porque os extremamente pobres raramente são atendidos pelas políticas públicas existentes, pois propositadamente, não são vistos, todos os seus laços foram cortados: os econômicos, sociais, políticos, afetivos, levando-os a invisibilidade social.

O fundamento dessa exclusão social só se entende a partir de aspectos históricos e econômicos de um sistema que, na contemporaneidade, está dada pelo fenômeno da crise do salário e emprego no capitalismo, que impôs fragilidades de toda ordem como, por exemplo, a produção de novos marginalizados a partir dos desempregados e subempregados (CASTEL, 1997, 1998). 
Muitos dos novos e antigos trabalhadores, agora desempregados, passam a viver com o mínimo de renda com a qual mal conseguem sobreviver. Essa "privação e falta de recursos" que lhes garantam a subsistência, a moradia, saúde, segurança, educação (COSTA, 2007, p. 27 apud, FRANCISCO, 2012, p. 2) é uma situação de vulnerabilidade que, se não houver uma política pública de incentivo à produção e renda, essas pessoas, que não são poucas, adentrarão em uma situação de pobreza que beira a zona do desfiliamento. A atual crise do trabalho assalariado, que engendra essa situação tem instalado muitos equívocos principalmente aquele que diz respeito a crença de que a pobreza, em seus variados graus, é uma condição apenas desse momento histórico, da sociedade capitalista quando, na verdade, não é; o que existe é um aprofundamento da questão social, que sempre esteve forjada na história da humanidade (CASTEL, 1998).

Tanto é verdade, que as ciências humanas, ao tomarem a pobreza como categoria e investigá-la, afirmam que, histórica, social e economicamente, ela foi se constituindo ora como um problema filantrópico, ora como social, político e, por fim, econômico. Este último é o que perdura na contemporaneidade e está diretamente ligada a posse ou não de bens, de recursos e proventos. A pobreza como condição política traz a ideia que ela só seria eliminada quando os direitos e deveres de todos fossem respeitados, essa concepção está na base da noção de sujeito de direito muito presente nos processos reivindicatórios de pessoas e grupos a quem são negados alguns direitos. Mas, como sabemos, é no capitalismo que a pobreza se extrema, a ponto dos marxistas defenderem a extinção desse sistema e assim estariam também eliminando a pobreza (SOUSA, 1999).

No neoliberalismo, o livre mercado busca suprimir o papel do Estado no que diz respeito à regulamentação da economia e da vida social como um todo, insiste em afirmar que a pobreza é uma condição individual, ou seja, as pessoas são pobres porque não trabalham por conta de uma "[...] disfunção individual, atribuída à ausência de disposição física, de iniciativa, de sorte, de aptidão para atuação na sociedade.”, ou seja, elas estão nessa situação porque querem e não como uma contradição do capital e trabalho (SOUSA, 1999, p. 86).

A educação entra nesse processo com o dever de potencializar a mão de obra considerada um capital (humano) que se valoriza por intermédio do investimento em qualificação; subjacente a essa ideia, está aquela que toma a escola como lugar de redenção da pobreza. Mas, embora a ausência de uma escolarização ajude, em parte, a compreender a pobreza, há que se falar que ela não é uma variável causal (FILGUEIRAS; GONÇALVES, 2011), não produz o pobre e a pobreza, contribui quando a escola não tem qualidade, segrega, não assume sua função precípua de internalização de conhecimento; isso termina por produzir 
um contingente de jovens com baixíssimos conhecimentos e habilidades básicas, o que implica na fragilização de sua sociabilidade; são, por força da lei, encaminhados a EJA engrossando as estatísticas do semianalfabetismo.

Essas análises iniciais nos levam a refletir sobre o lugar das pessoas em situação de vulnerabilidade ou de desfiliamento social na Educação de Jovens e Adultos e na Educação Social, como essas educações percebem esses sujeitos, que práticas são viabilizadas e com que intenção. Vamos, neste texto, analisar tais questões como forma de trazer para a ordem do dia uma reflexão em torno desses novos (antigos) sujeitos da EJA que sempre foram ignorados por essa educação, mas presenciados na ES.

\section{As pessoas em vulnerabilidade e desfiliamento social: novas categorias, velhos problemas.}

Quem são os sujeitos da EJA? Essa é uma questão que vários educadores tem feito, mas nem sempre conseguem definir, pela pesquisa e reflexões pedagógicas, porque cada dia cresce o número de pessoas em situações sociais diversas que não logram exito da educação regular e que passam a ser, legalmente, sujeitos dessa educação. O fenômeno da juvenilização da EJA, por exemplo, contribui para isso, pois cada dia mais jovens adentram nas classes de EJA, provocando inchaços quase incuráveis por conta de que ela não está, infelizmente, preparada para lidar, pedagogicamente, com o jovem.

A EJA ainda continua sendo também lugar de inclusão excludente (KUENZER, 2005), em que no primeiro momento o jovem e o adulto é incluído nas classes de EJA, mas dado a fragilidade pedagógica presente nos processos de ensino-aprendizagem termina por excluir essas pessoas, não as promovendo cognitiva e socialmente; sendo que esse fato é sustentado pelo fenômeno da aprovação reprovada, em que os sujeitos são promovidos nas avaliações da aprendizagem, mas sem a aquisição de conhecimentos científicos, culturais, saberes e habilidades.

Isso vulnerabiliza tanto a EJA que, socialmente, ainda é percebida como uma educação menor para os menos e mais pobres, mas, ela precisa sair dessa concepção, abandonar esse peso morto e assumir práticas e "sujeitos concretos, em contextos concretos, com histórias concretas, com configurações concretas. Sendo que qualquer tentativa de diluílos em categorias muito amplas os desfigura. Eu diria que os últimos anos foram tempos de deixar, ainda, mais recortadas essas configurações do que venha a ser jovem e adulto popular" (ARROYO, 2007, p. 7). 
Assumi, diríamos, novos sujeitos concretos, antes rejeitados por ela, como as pessoas em situação de desfiliamento ou vulnerabilidade, respectivamente, representados pelos mendigos, moradores de rua composto por crianças, adultos e velhos abandonados dentre outros; os que estão em fragilidade social grande que, embora não estejam ainda na indigência, se nada for feito chegarão a essa situação pela instabilidade social, produtiva e pessoal em que estão, vivendo muitos em situações extremamente humilhantes, como é o caso de jovens e adultos em drogadição, de homens e mulheres em situação de prostituição, crianças e adolescentes de rua, adolescentes e adultos em privação e restrição de liberdade, dentre outras.

Esses também são sujeitos da EJA que estão, concretamente, vivendo em situações desumanas, entender as situações é o primeiro passo para instituir uma educação humanizadora.

As muitas situações de vulnerabilidade se parecem com a de desfiliamentos, como, por exemplo, os adolescentes, jovens e adultos que estão em restrição ou privação de liberdade, quando pensamos que eles estão sendo, mesmo que precariamente, atendidos pelas políticas sociais de (re) integração. Logo não podemos classificá-los como vulneráveis, tão somente de assistidos, porém sabemos que, tutelados pelo Estado ou atendidos em programas sociais, continuam em situação de fragilidade da vida e das relações sociais que acompanham, pois quem ainda não ouviu em noticiários que pessoas sobre a tutela do Estado foram mortas nas diversas instituições pela ausência da garantia inalienável de segurança?

Nesse sentido, não é fácil categorizá-los sociologicamente posto que as situações são metamorfósicas e escorregadias, então como classificar os muitos indigentes, inválidos, abandonados, desamparados, delinquentes, drogados nas novas categorias da vulnerabilidade, desfiliamento, assistidos e integrados socialmente? (CASTEL, 1997; 1998; 2000; 2011), mesmo tais categorias terem maior poder de representar as facetas da exclusão social, já que elas apresentam um duplo eixo que as determinam: trabalho e inserção relacional que produz três zonas: integração: significa que a pessoa tem uma participação forte no mundo do trabalho, consequentemente, tem inserção relacional forte; a vulnerabilidade é o contrário, a pessoa tem uma participação precarizada no mundo do trabalho, também tem uma inserção relacional frágil e no desfiliamento não há participação do mundo do trabalho, a pessoa vive isolada, pois todas os vínculos sociais foram cortados pela situação de indigência em que vive (CASTEL, 1998; 1997).

A zona de desfiliamento explica as duas situações de indigência: a invalidez e a vagabundagem. A primeira é quando a pessoa recebe algum tipo de proteção porque as suas 
condições materiais não permitem trabalhar, seja por problema de saúde ou idade; a segunda é quando a pessoa não trabalha, mesmo tendo condições, e não recebe proteção nem do Estado e nem da sociedade civil organizada (CASTEL, 1997). É na zona de vulnerabilidade que esta a possibilidade da pessoa entrar ou sair das zonas de integração ou de desfiliamento, isso vai depender de toda uma rede de proteção que impeça a exclusão total.

A zona de vulnerabilidade é estratégica porque é a instância em que as políticas públicas devem atuar para salvar da indigência parte da população. Ela é um "espaço social de instabilidade, de turbulências, povoado de indivíduos em situação precária na sua relação com o trabalho e frágeis em sua inserção relacional" (CASTEL, 1997, p. 26), exigindo atenção especial por parte também da sociedade civil na adoção de atitudes e de ações que evitem que os indivíduos e grupos adentrem na zona de desfiliação, que requer mais dispêndios de ações, como é o caso daquelas pessoas que se encontram na mendicância, abandonadas nas ruas das grandes cidades, geralmente em idade avançada, em precária condição de vida objetiva e subjetiva.

Nesse sentido é que a categoria exclusão social não dá mais conta de representar, definir e identificar os marginalizados da sociedade, porque toma a marginalização como situação única, não fazendo a necessária diferenciação interna (CASTEL, 1998); portanto sendo, atualmente, um termo impreciso que escamoteia a complexidade da questão social quando aponta para elementos visíveis da crise e não para os estruturais a partir da desestabilização do trabalho e salário. Seu uso já deveria ter sido abolido, pois “[...] designa um número imenso de situações diferentes, encobrindo a especificidade de cada uma. Ou seja, a exclusão não é uma noção analítica. Ela não permite conduzir investigações precisas sobre os conteúdos que pretende abranger" (CASTEL, 2000, p. 18).

No entanto, esse questionamento em torno da categoria exclusão social não quer dizer que o fenômeno em si deixou de existir, ou que seus sintomas foram amainados; pelo contrário, apenas que a situação se tornou mais complexa devido à crise estrutural do capital que vem produzindo novas marginalidades e ressignificando outras quando

[...] afetou a condição salarial: o desemprego em massa e a instabilidade das situações de trabalho, a inadequação dos sistemas clássicos de proteção para dar cobertura a essas condições, a multiplicação de indivíduos que ocupam na sociedade uma posição de supranumerários, inempregáveis, inempregados, ou empregados de um modo precário, intermitente. De agora

\footnotetext{
${ }^{1}$ Segundo Castel (1998), a questão social é um termo que surge na época da Revolução Industrial, significando que no bojo das transformações econômicas, sociais, políticas houve também rupturas e contradições no seio da relação trabalho e capital, que comprometia o desenvolvimento como, por exemplo, a pauperização da classe trabalhadora que se tornou vítima dessa Revolução.
} 
em diante, para muitos, o futuro é marcado pelo selo do aleatório. (CASTEL, 1998 , p. 21 - grifo do autor).

A crise estrutural do capital fratura a sociedade, implantando problemas de toda ordem, em todos os setores da vida produtiva, social, política, empurrando "para o primeiro plano as temáticas da precariedade, da vulnerabilidade, da exclusão, da segregação, da vulnerabilidade" (CASTEL, 1998, p. 22), ampliando, sobremaneira, a existência dos supranumerários de uma nação e do mundo, que são aqueles que vivem em situações de marginalidade permanente, são invisíveis, supérfluos, mas "estão bem presentes - e isso é o problema, pois são numerosos demais" (CASTEL, 1998, p. 33). A minimizar da situação marginal dos supranumerários estaria nas políticas de inserção e integração social, que reduziram as distâncias que separam as zonas de vulnerabilidade e desfiliamento da zona de integração. Tais políticas de inserção são formas legitimas e mais atuante de enfrentamento das questões sociais, constituindo uma zona de intervenção reparadora (CASTEL, 2000), que protege os que estão na marginalidade por ser um "conjunto de empreendimentos de reequilíbrio para recuperar a distância em relação a uma completa integração (um quadro de vida decente, uma escolaridade normal, um emprego estável etc.)" (CASTEL, 1998, p. 538), mas, para além dessa inserção, é preciso também a formulação de políticas essencialmente integradoras - aquelas que são

[...] animadas pela busca de grande equilíbrios, pela homogeneização da sociedade a partir do centro. São desenvolvidas através de diretrizes gerais num quadro nacional. É o caso das tentativas para promover o acesso de todos aos serviços públicos e à instrução, uma redução das desigualdades sociais e uma melhor divisão das oportunidades, o desenvolvimento das proteções e a consolidação da condição salarial. (CASTEL, 1998, p. 538).

As políticas sociais teriam o poder de inserir e de integrar essas pessoas nas redes existentes de sociabilidade, sendo elas, no contorno do capital, o remédio contra as diferentes e diversas situações de marginalização que vêm rompendo com a coesão social, a solidariedade orgânica da sociedade (CASTEL, 1998). Mas as políticas de inserção e de integração como ações que concedem direitos e evitam que o sujeito adentre em zonas de fim de um percurso, não rompem com a lógica capitalista da propriedade privada dos meios de produção, pelo contrário, fortalecem-na, pois são corretivos marginais (MÉSZÁROS, 2005), em que o capital faz algumas correções previstas para reparar os seus defeitos em vários âmbitos do mundo social e do trabalho.

O sistema e todo o seu aparato ideológico continua, aparentemente, seguindo, inabalável, as muitas crises, reivindicações e as questões sociais. A concepção de política 
inserção e integração subjacentes às políticas sociais esconde a verdadeira intenção acomodar as diversas marginalidades, permitindo que o capital siga o seu curso de reprodução.

Fica evidente que as políticas sociais, direcionadas às crianças, adolescentes, jovens, adultos e velhos, em situação ou não de vulnerabilidade, são para corrigir os defeitos de um sistema, mas, no caso do Brasil, nem sempre tais políticas conseguem surtir efeitos, porque não são de integração social, embora se apresentam como resgatadoras de dividas sociais. Mas quando observamos os programas que tentam corporificar essas ideias, percebemos que são desenvolvidos equivocadamente, seja na ordem do pensamento, das ações ou da profissionalidade das pessoas e instituições executoras. O resultado: integração social não se verifica, concretamente, devido a descontinuidade dos programas, bem como pela ausência de um acompanhamento e avaliação governamental e da própria sociedade. E no fim desse processo, as pessoas atendidas por essas políticas adentram na zona de desfiliamento, e ainda são responsabilizadas por tal situação, porque que não soube, supostamente, aproveitar as oportunidades de reintegração e reinserção social oferecidas pelo Estado.

A zona de vulnerabilidade e desfiliamento social no país é bastante profunda, por conta da não existência de uma rede consolidada de política de inserção e integração, pois ainda são muitos os que vivem em situações sociais fragilizadas, numa indigência que elimina qualquer condição humana e o Estado não sabe muito o que fazer com o mendigo, com o morador de rua, com o andarilho de saúde mental fragilizada; com a mulher e o homem em situação de prostituição; a criança de rua e aquela em situação de trabalho infantil; o adolescente em restrição e privação de liberdade, o jovem que se droga, trafica, prostitui, rouba; o adulto que alicia os jovens, que chefia o tráfico, que está em condição prisional; a mulher e o homem que sofrem os horrores do tráfico humano, do trabalho escravo e tantas outras situações.

Em relação a educação são quase inexistentes as políticas educativas que atendam as necessidades de formação dessas pessoas, às vezes, elas são mera e esporadicamente mencionadas em algumas políticas, outras vezes apenas configuram-se no rol dos sujeitos da educação básica, como é o caso da Educação de Jovens e Adultos; mas, efetivamente, os programas de alfabetização e escolarização mais ampla de jovens e adultos não são pensados para e com eles e na perspectiva de uma tecnologia social, educacional, cultural adequada. A solução desse fato está na responsabilização do Estado em efetivar políticas em todos os âmbitos, assegurando para os jovens e adultos em situação de vulnerabilidade social os direitos corriqueiramente defendidos para todos. 


\section{Educação de jovens e adultos: os mesmos dilemas e exclusões}

Nas políticas educacionais, as pessoas em situação de vulnerabilidade e desfiliamento aparecem como seres genéricos, idealizados, mas, para além disso, precisam ser configurados nas demandas dos que precisam de alfabetização e escolarização ampla. Concretamente, no entanto, as ações existentes não os contemplam, por exemplo, o Programa Brasil Alfabetizado - PBA (BRASIL, 2007), criado em 2003 e reformulado em 2007, não identifica quem é esse jovem e o adulto que deve ser alfabetizado, portanto não tem como saber se por acaso os indigentes são atendidos. E mesmo em fase da VI Conferência Internacional de EJA, reconhecer essas pessoas e os diferentes tipos de exclusão e conclamar o governo e a sociedade civil a lutarem na solução do problema, o que vemos é ainda uma letargia na inclusão dessas pessoas em programas existentes de EJA, mesmo a CONFITEA expressamente afirmando que se trata de uma educação composta por um

[...] conjunto amplo e heterogêneo de jovens e adultos oriundos de diferentes frações da classe trabalhadora. Por isso, é compreendido na diversidade e multiplicidade de situações relativas às questões étnico-racial, de gênero, geracionais; de aspectos culturais e regionais e geográficos; de orientação sexual; de privação da liberdade; e de condições mentais, físicas e psíquicas - entendida, portanto, nas diferentes formas de produção da existência, sob os aspectos econômico e cultural. Toda essa diversidade institui distintas formas de ser brasileiro, que precisam incidir no planejamento e na execução de diferentes propostas e encaminhamentos na EJA. (BRASIL, 2009, p. 28).

Refletir sobre a EJA como lugar de inclusão social é condição primeira para garantir o direito a essas pessoas a alfabetização, escolarização ampla, profissionalização, assistência social, psíquica etc., que os integrem ao mundo social e produtivo dignamente, pois não é suficiente apenas reconhecer que "o mapa do analfabetismo e dos sujeitos pouco escolarizados se confunde com o mapa da pobreza em nosso país, consequência do processo de exclusão social causado pelo sistema capitalista" (BRASIL, 2009, p. 30). É preciso uma práxis na EJA que permita a inclusão desses como sujeitos de direitos, cumprindo as determinações do Art. $4^{\circ}$ da Declaração Mundial sobre Educação Para Todos quando diz que

Os grupos excluídos - os pobres: os meninos e meninas de rua ou trabalhadores; as populações das periferias urbanas e zonas rurais os nômades e os trabalhadores migrantes; os povos indígenas; as minorias étnicas, raciais e linguísticas: os refugiados; os deslocados pela guerra; e os povos submetidos a um regime de ocupação - não devem sofrer qualquer tipo de discriminação no acesso às oportunidades educacionais. (UNESCO, 2015, p. 4). 
Sabemos que a ausência dessas pessoas nas políticas educacionais como um todo é histórica e isso merece uma cuidadosa análise de cunho investigativo que aponte as causas dessa exclusão, pois, “[...] por décadas esses jovens e adultos são os mesmos, pobres, oprimidos, excluídos, vulneráveis, negros, das periferias e dos campos. Os coletivos sociais e culturais a que pertencem são os mesmos", isso se é um determinante presente na "história da sua educação do que a indefinição, imprevisão e diversidade de atores, de ações, espaços e intervenções" (ARROYO, 2005, p. 33). O fundamento dessa exclusão escolar se encontra na própria ideologia subjacente a educação formal desde o período colonial até o século XVIII, qual seja, era um artigo de luxo que só deveria ser ofertada aos filhos das elites, isso se verificou também no período da economia agrária comercial exportadora à industrial, embora houvesse ações, mesmo que fragilizadas e esparsas, em prol de estabelecer uma educação pública elementar, secundária e universitária (RIBEIRA, 1982).

Em relação à Educação de Adultos (EA), somente no século XX, especificamente, a partir do Estado Novo, é que ela se torna um problema nacional quando da necessidade do país assumir outro modelo de desenvolvimento econômico (BEISIEGEL, 1974), já que os altos índices de analfabetismo da população brasileira era um entrave ao progresso, pois as estatísticas demonstravam que em 1890 o analfabetismo estava em torno de $85 \%$ e em 1920 de $75 \%$ em números absolutos de crianças, adolescentes e adultos; entre os que estavam com 15 anos em 1920 o índice era de 65\% (RIBEIRO, 1982). Esses índices indicavam que o país fracassava na tarefa do ensino elementar e secundário e que não tinha uma política de educação de adultos de enfrentamento dessa situação; isso se tornava um problema para o processo de industrialização nacional que estava aproveitando as brechas deixadas pela Segunda Guerra Mundial para modernizar sua economia, avançando em direção a um outro modelo de desenvolvimento (POCHMANN, 2004).

O Estado passa a ter, então, mais preocupação com a EA, em 1945 lança a Campanha de Educação de Adolescentes e Adultos (CEAA) que deveria reduzir os índices de analfabetismo, mas, mesmo com significativo avanço em termos de uma política pública concreta de educação de adultos, infelizmente, tal Campanha não concretizou os objetivos esperados (PAIVA, 1987). Nos governos militares e da redemocratização do país, outras políticas foram gestadas, porém fracassaram por diversas questões como, por exemplo, indefinição de financiamento público para a EA, fragilização das práticas educativas e descontinuidade das ações financeiras e pedagógicas quando da mudança de orientação política (PAIVA, 1987; HADDAD; DI PIERRO, 2000). 
E até hoje, mesmo a Lei de Diretrizes e Bases da Educação (LDBEN), n 9.394/96 tendo sacramentado, equivocadamente, a unicidade entre Educação de Adultos (EA) e a Educação de Jovens (EJ) na denominação EJA, essa educação ainda não caminha para uma institucionalidade como política de Estado, embora o atual Programa Brasil Alfabetizado (PBA), criado em 2003, tenha essa pretensão, iniciando pela universalização da alfabetização de todas as pessoas acima de 15 anos. (BRASIL, 2007) Para tanto, outras políticas de complementação ao PBA foram instituídas como o Projeto Escola de Fábrica e o PROJOVEM a fim qualificar jovens para o mercado de trabalho como forma de concretizar a relação trabalho e educação, bem como o Programa de Integração da Educação Profissional e Ensino Médio para Jovens e Adultos (PROEJA) que busca dar uma formação profissional técnica integrada ao ensino médio.

Mas, infelizmente, apesar de alguns avanços, essas ações padecem dos mesmos problemas daqueles verificados nas ações: do Movimento Brasileiro de Alfabetização (MOBRAL) de 1967, da Fundação Educar 1985, e do Programa Alfabetização Solidária (PAS) de 1996, que pretendiam erradicar o analfabetismo e inserir jovens e adultos no mercado de trabalho (RUMMERT; VENTURA, 2007). O que tem marcado a história da EA no país é a fragilidade política e pedagógica “[...] fortemente marcada pelo aligeiramento, destinada, predominantemente, à correção de fluxo e à redução de indicadores de baixa escolaridade e não à efetiva socialização das bases do conhecimento" (RUMMERT; VENTURA, 2007, p. 33).

Essa educação nem mesmo tem se mostrado como um corretivo marginal (MÉSZARÓS, 2005), posto que o Estado não reconheceu ainda, na prática, que vem falhando em não garantir escolarização para todos (PEREIRA, 2010), embora propague, oficialmente, que a redução das taxas de analfabetismo no país decresceu, já que em 2002 era de 11,9\% da população absoluta, 2009 de 9,7\% e 2012 de 8,7\% (BRASIL, 2010; 2013). Mas o interessante é que essas estatísticas se contradizem quando demonstram que mais pessoas jovens engrossam as fileiras dos que não logram êxito na escola e passam, forçosamente, a serem alunos da EJA (HADDAD; DI PIERRO, 2000); no entanto parte desse novo público, inevitavelmente, adentrará na marginalidade social caso não haja uma política de inserção e integração.

Tal política em EJA, na concepção de educação geral e profissional integrada às outras, como a de trabalho, emprego e renda, moradia, saúde para todos os sujeitos dessa educação. Não se esquecendo da valorização financeira e formação inicial e continuada dos professores que atuam na EJA, para que o quadro de desprezo e de desqualificação dessa 
modalidade de ensino seja modificado, já que impera o improviso pedagógico e a leigalidade de professores, atuando nesse segmento sem formação adequada.

A leigalidade não se refere ao tradicional professor que não tinha formação para o magistério, mas atuava nele, aqui, o professor tem a formação, mas não a específica em EJA, atuando nessa modalidade de ensino de maneira muitas vezes improvisadas e por diversos motivos, por exemplo, cumprimento do tempo para a aposentadoria, doença ocupacional, segmento mais fácil por conta da pouca regulação pedagógica e de gestão do ensino noturno, punição por ter ido contra os interesse da gestão, movimentando grupos para greves, ou denunciando mal gerenciamento financeiro do dinheiro público para a educação etc.

Mas, não será uma tarefa fácil mudar esse quadro de oportunismo, subserviência e de desqualificação e, ao mesmo tempo, avançar na formação de professores exclusivos para a docência em EJA, que incorporem diversos conhecimentos científicos, culturais e de saberes da prática, as experiências de outras educações e contextos, como o da pedagogia social no trato das questões de marginalidade. Romper com as práticas e avançar serão uma árdua luta do grupo que pensa a EJA numa concepção de integradora social, visto que os cursos de pedagogia e as licenciaturas específicas não são voltadas para esse ensino e não há uma alternativa sob a responsabilidade do Estado, mas, independentemente das possibilidades, a EJA precisa assumir todos os seus sujeitos em diversas situações de marginalidade.

\section{Educação social: uma prática de inclusão socioeducativa}

A Educação Social se define pela práxis, seus sujeitos são todas as pessoas em situação de marginalidade, seu território são os espaços educativos não escolares e sua intencionalidade pedagógica é a mudança radical de vida social e produtiva dos seus sujeitos, para isso aposta em outras educações, pedagogias, assistências e políticas que completam o processo de ressocialização. A sua visão de homem e de mundo é aquela centrada no protagonismo do oprimido em que ele é "capaz de assumir-se como sujeito de sua história e da história, como agente de transformação de si, do outro e do mundo como fonte de criação, liberdade e construção dos projetos pessoais e sociais, numa dada sociedade, por uma prática social, critica, criativa e participativa" (GRACIANI, 2009, p. 223).

É uma prática que tem interesses e sujeitos, não se centra apenas no trabalho educativo com crianças, jovens, adultos e velhos em situação de marginalidade, mas aglutina outras situações e sujeitos, isto porque "a educação social compreende a educação de adultos, popular, comunitária, cidadã, ambiental, rural, educação em saúde e se preocupa, 
particularmente, com a família, a juventude, a criança e o adolescente, a animação sociocultural, o tempo livre, a formação na empresa, a ação social” (GADOTTI, 2012, p. 7).

Sua corporeidade é a partir de três critérios definidores dos contextos, como: o geográfico, o de idade e o social, sendo que o primeiro refere-se aos

[...] programas socioeducativos voltados para o atendimento ao bairro, quarteirão, comunidade, cidade; segundo critérios de idade volta-se para grupos de crianças, adolescentes, jovens e adultos e até idosos, que compartilham necessidades especificas; segundo critérios sociais, a educação social se dirige a grupos que compartilham dificuldades, riscos e necessidades comuns e específicas (uso de drogas, situações de pobreza, violência urbana, envolvimento com gangues antissociais etc.). (CALIMAN, 2009, p. 357).

A ES trabalha com a mudança da situação desumana de jovens que usam crake e se encontram mortificados nas ruas das grandes, médias e pequenas cidades brasileiras; de homens e mulheres que sobrevivem da prostituição em espaços degradados da cidade, muito diferente de um seleto grupo de garotos e garotas de programas que fazem uso dessa atividade para pagar estudos universitários, de mendigos que se encontram em uma situação (i)material deplorável: corpos fedidos, doentio e em chagas; de moradores de rua que ficaram ou nasceram sem habitação, de presos que ficam durante muito tempo na prisão e que quando saem dessa situação estão sem perspectiva de vida não mais acreditando que podem viver fora da prisão.

A base epistemológica da ES é a freireana porque busca a libertação dessas pessoas, restabelecendo vínculos sociais, afetivos e produtivos no contexto em que vivem, constituindo-se como uma educação ressocializadora que busca construir um tipo de

[...] cidadania sedimentada nas garantias de direitos, como o de alimentação, moradia digna, emprego e renda, escolarização geral, dentre outros. Essa pedagogia está na linha de frente no enfrentamento da pobreza, da marginalização e exclusão de pessoas na sociedade contemporânea, por isso seu conceito dá conta dessa e de outras dimensões sempre aliadas à ideia de trabalho social e de educação para a promoção social. (PEREIRA, 2013, p. $11)$.

Há que se afirmar que embora a ES seja vista como uma prática de readaptação social, não significa que seja dentro da ordem estabelecida, pelo contrário, para além, porque se entende que é pela superação desta que será possível a existência de uma sociedade igualitária. Na linha da pedagogia do oprimido é que a educação social se legitima, pois Paulo Freire foi 
[...] um grande inspirador da Pedagogia Social mesmo sem ter usado esse termo em seus escritos. Para ele, a pedagogia social caracteriza-se como um projeto de transformação política e social visando ao fim da exclusão e da desigualdade, voltada, portanto, para as classes populares (como pedagogia popular e libertadora), inserindo-a, portanto, no campo das pedagogias da práxis ao lado de Pistrak (1981); Makarenko (2005); Freinet (1974); Gramsci (1976), Bogdan Suchodolski (1971), Maria Teresa Nidelcoff (1994) e outros. (GADOTTI, 2012, p. 26 - grifo do autor).

A teoria pedagógica de Freire lastreia a reflexão da prática educativa social, ajudando a pensar o inusitado dessa ação, permitindo-lhe a construção do novo e do necessário educativo, sempre na intencionalidade do empoderamento das pessoas em situação de vulnerabilidade e desfiliamento. O empoderamento (empowerment) está dialeticamente imbricado com a noção de conscientização e diz respeito à transformação social, possibilitada por um coletivo que se liberta a partir de um processo educativo problematizador da situação histórica, política e social vivenciada por esse coletivo (FREIRE; SHOR, 1986). Por isso a educação social não visa ensinar conteúdos, mas empoderar as pessoas para que tomem a direção de suas vidas na intenção da coletividade. O empoderamento objetiva que a

[...] classe trabalhadora, através de suas próprias experiências, sua própria construção de cultura, se empenha na obtenção do poder político. Isto faz do empowerment muito mais do que um invento individual ou psicológico. Indica um processo político das classes dominadas que buscam a própria liberdade da dominação, um longo processo histórico de que a educação é uma frente de luta. (FREIRE; SHOR, 1986, p. 72).

A educação para o empoderamento intenciona a conscientização crítica que seria a ultrapassagem da "esfera espontânea de apreensão da realidade, para chegarmos a uma esfera crítica na qual a realidade se dá como objeto cognoscível e na qual o homem assume uma posição epistemológica” diante da vida e do mundo (FREIRE, 1979, p. 26). Nesse aspecto, é que o "social da educação e pedagogia social assume rigor epistemológico e prático porque denuncia as contradições vividas na sociedade atual capitalista e, ao mesmo tempo, anuncia possibilidades de superação dessas contradições sociais, e que são históricas, pela via da educação.” (PEREIRA, 2013, p. 11 - grifo do autor)

O social ao adjetivar a Pedagogia Social "coloca em questão a própria pedagogia. Então não se trata apenas de uma nova tendência nas correntes da história das ideias pedagógicas. Trata-se de um novo paradigma. Com isso ela coloca em questão o próprio "modelo" da educação adotado pelo capitalismo que nega o social e sobrevaloriza o econômico." (GADOTTI, 2012, p. 27). 
A ES se corporifica em diversas ações, com metodologia própria e sempre levando em consideração a situação dos sujeitos, motivo principal de sua existência. Assim, também pertencem a esse campo as práticas educativas com meninos e meninas de rua, com pessoas em situação de prostituição, com pessoas idosas institucionalizadas, jovens em restrição de liberdade, pessoas de comunidades tradicionais, moradores de rua, pessoas em situação de albergues públicos, em situação hospitalar, dentre outros. Essas práticas são estudadas, teorizadas, cientificamente, pela pedagogia social que busca refletir sobre elas, desvelando as contradições.

O objeto da ES é a "prática educativa social em sua multidimensionalidade ou, como preferimos chamar, de contextos educativos, já que cada prática se vincula a um contexto social, político e pedagogicamente situado, bem como referenciado por um tipo de sujeito que se encontra em situação de vulnerabilidade social" (PEREIRA, 2014, p. 133). Não é uma educação recente, nasce na Alemanha por volta de 1850 quando Diesterweg que escreve um pequeno manual sobre as suas bases pedagógicas; em 1854 Karl Mager utiliza o termo Pedagogia Social (MACHADO, 2009).

Em 1898 é conotada como a ciência da ES quando Paul Nartop escreve o livro intitulado de Pedagogia Social com um forte viés kantiano afirmando que essa pedagogia era a ciência $d a$ e para a comunidade, já que é nesta que o homem se torna homem, se humaniza. É uma pedagogia que nasce para resolver os problemas de socialização e ressocialização de crianças, jovens, adultos e velhos que viviam em condições de pobreza extrema, sendo que essa condição fora dada, em parte, aos conflitos de unificação política e geográfica daquele país (LARROYO, 1970).

Essa educação e pedagogia influenciaram muitos países da Europa no Século XX que passavam por diversos problemas sociais oriundos da revolução industrial, de conflitos e guerras, de crises econômicas internas, de restrição da liberdade política dentre outros fenômenos. No Brasil, o termo não era usual, embora a prática existisse com o nome de educação popular na vertente freireana e somente no final do Século XX e XXI é que começa a despontar nas publicações a partir de trabalhos com meninos de rua e outros grupos marginalizados.

Atualmente chamamos de Educação e Pedagogia Social toda e qualquer prática e teoria educativa direcionada a pessoas e grupos em situação ou não de vulnerabilidade e desfiliamento social. Existe uma relação dialética entre a educação social como prática e a pedagogia social como teoria no desenvolvimento da práxis educativa social, visto que "a pedagogia social, oferecendo bases teórico-metodológicas para a prática da educação social, 
favorece o desenvolvimento da educação social e, ao mesmo tempo, a prática da educação social sistematizada pela pedagogia social, favorece o desenvolvimento dessa pedagogia." (GADOTTI, 2012, p. 26).

\section{EJA e Educação Social: uma relação possível?}

Pensar dialeticamente na relação entre ES e PS é algo natural e necessário para o crescimento do campo das práticas educativas sociais, mas essa mesma reflexão é possível realizar quanto se trata da ES e da EJA? É uma relação possível diante de tudo o que já foi analisado? Acreditamos que sim, pois ambas tem como sujeitos as pessoas em situação de marginalidade, isso já é por si só um elemento de aproximação pedagógica, além disso, uma começa quando ainda não termina a outra no sentido da prática: ressocialização e escolarização concomitantes.

A ES como uma prática anterior e concomitante a EJA é a possibilidade de uma educação mais eficiente, pois entendemos que não dá, por exemplo, para alfabetizar e desenvolver o letramento sem antes um trabalho educativo, fundado na problematização da situação vivida pelos oprimidos, capaz de mudar suas representações da situação vivida, criando desejos e possibilidade outras de vida (i)material. Embora o trabalho educativo social, embora não vise o ensino de conteúdos escolares, não significa que os despreze; pelo contrário, adota aqueles relacionados aos problemas pessoais e sociais enfrentados pelos educandos, estes são trabalhados em uma perspectiva pedagógica freireana em que se busca problematizar esses conhecimentos com vistas a conscientização critica e mudança de vida (i)material, não para nessa prática, mas continua na garantia da escolarização plena, de qualidade e no contexto da pedagogia libertadora.

Nesse sentido, não temos dúvida de que o estabelecimento da relação dialética entre a ES e a EJA deve se dá na perspectiva da pedagogia problematizadora de fundamento freireano entendo que não é a aplicabilidade desse pressuposto, mas a sua ressignificação a partir das necessidades dos sujeitos e contextos sociais conflitantes e sempre na intencionalidade da mudança radical, mesmo que uma ou outra chame para o oposto disso. Resumidamente, a problematização como categoria principal da pedagogia freireana e que é validada por outras pedagogias, fundamenta-se na seguinte práxis:

[...] realização de estudo do contexto/realidade individual e coletiva, seja de pessoas, de grupos ou de circunstâncias; cria situações de aproximação sucessiva com a realidade através de diversos ângulos (leitura dos textos, 
fatos, fotos, depoimentos) de modo a conhecer seus contornos e as múltiplas leituras. Assim, a problematização pode conduzir a demandas de ações e de intervenções. Nessa direção, problematizar é mais que construir perguntas ou que dar respostas a perguntas, mas também um requerimento de reflexão, de discussão, de estudos, realização de levantamentos e estudos dos materiais disponíveis. (SANTIAGO; BATISTA NETO, 2011, p. 10).

Sem problematização não será possível a relação entre a ES e a EJA no trato educativo com as pessoas em situação de vulnerabilidade, questões precisam ser evidenciadas, como: qual o contexto conflitante provocador das vulnerabilidades e desfiliamentos? Que leituras desse mundo serão desveladoras da realidade para esses sujeitos em processo educativo? Que noção de sujeito histórico, econômico e social será referenciado? Que técnicas e métodos pedagógicos melhores se aplicam para entender e mudar essa realidade? Dentre outras questões fundamentais para a mudança radical de vida dessas pessoas.

Ratificamos que a intencionalidade no trato do conhecimento pedagógico freireano não é a sua aplicabilidade, mas a reflexibilidade que permite a presença constante da práxis pedagógica - aquela capaz de transformar as condições objetiva e subjetiva dos oprimidos, portanto, é uma educação que "sofre a influência da obra de freireana e reitera a importância do conhecimento de mundo para a sua transformação por meio de um, processo educativo dialógico, rigoroso, intuitivo, imaginativo, comunicativo, participativo e afetivo." (GRACIANI, 2014, p. 18).

Nesse aspecto, a EJA tem muito a aprender com a ES, caso estabeleça uma relação dialética de complementação: escolarização - ressocialização, o que possibilitará incluir essas pessoas nos processos formais da escola regular, já que queiramos ou não a EJA formalizada na LDBN 9394/96 está restrita “[...] ao contexto escolar, excluindo o conceito de educação profissional e outras modalidades da Educação Social (sócio-educação; educação comunitária; educação prisional, medidas sócio-educativas, educação para a paz; entre outras)" (STRECK; SANTOS, 2011, p. 21).

A ES resgata o sentido de inclusão social da EJA quando abre possibilidade de trabalhar com os mais pobres dos pobres, recuperando nestes "o sentido de pertencimento do sujeito - jovem e adulto - nas suas relações mais amplas com a comunidade, percebendo seu potencial de transformação." (STRECK; SANTOS, 2011, p. 34).

Não há dúvida, portanto, de que a ES tem condições ontoepistêmicas de assumir um lugar central na EJA, posto que esta precisa escolarizar um coletivo muito grande de sujeitos com demandas pessoais e sociais próprias e, ao mesmo tempo, genéricas, mas que sozinha não dará conta desse fazer. Associada a ES, porém, concretizará um quefazer capaz de 
enfrentar as questões sociais. Isso significa que está na educação social a possibilidade de "[...] elaboração de suportes teóricos e metodológicos de intervenção no campo da educação geral e, especialmente, no campo da Educação de Jovens e Adultos.” (STRECK; SANTOS, 2011, p. 30).

É imperioso que a EJA se alie a práticas educativas exitosas e assuma contextos e sujeitos educativos diversificados para concretizar os imperativos da função reparadora (garantir o direito à educação às populações que tiveram esse direito negado), equalizadora (garantir com esse direito um equilíbrio social e econômico entre os diversos grupos, de maneira a diminuir as diferenças sociais, a exclusão) e permanente (que esse direito seja pleno e amplo de qualificação e requalificação para o mundo do trabalho e social, de maneira contínua e ao longo da vida das pessoas) como sugere o Parecer CEB 11/2000 (BRASIL, 2000).

Não será uma tarefa fácil dados os ranços que a EJA guarda no seu interior, mas continuando na mesma fé freireana de que a educação problematizadora é a possibilidade de um mundo melhor, nisso "há uma esperança, não importa que nem sempre audaz, nas esquinas das ruas, no corpo de cada um e de cada uma de nós.” (FREIRE, 1992, p. 10).

\section{REFERÊNCIAS}

ARROYO, Miguel. Educação de Jovens e Adultos: um campo de direitos e de responsabilidade pública. In: SOARES, Leôncio; GIOVANETTI, Maria A.; GOMES, Nilma L. Diálogos na educação de jovens e adultos. Belo Horizonte/MG, Autêntica, 2005, p. 1950 .

ARROYO, Miguel. Balanço da EJA: o que mudou nos modos de vida dos jovens-adultos populares? REVEJ@ - Revista de Educação de Jovens e Adultos, v. 1, n. 0, p. 1-108, ago. 2007.

BEISIEGEL, Celso de Rui. Estado e educação popular: um estudo sobre educação de adultos. São Paulo: Pioneira, 1974.

BRASIL, Ministério da Educação, Conselho Nacional de Educação. Parecer CEB n. 11/2000. Institui Diretrizes Nacionais para a Educação de Jovens e Adultos. Brasília. Dário Oficial da União 10 de maio de 2000.

BRASIL, Presidência da República. Casa Civil. Subchefia para Assuntos Jurídicos. Decreto $\mathrm{n}^{\circ}$ 6. 093, de 24 de abril de 2007. Dispõe sobre a reorganização do Programa Brasil Alfabetizado, visando a universalização da alfabetização de jovens e adultos de quinze anos ou mais, e dá outras providências. Brasília. Diário Oficial da União, 25 de abril de 2007. 
BRASIL, Ministério da Educação. Secretaria de Educação Continuada, Alfabetização e Diversidade. Diretoria de Políticas de EJA. Programa Brasil Alfabetizado. Princípios, diretrizes, estratégias e ações de apoio ao Programa Brasil Alfabetizado: elementos para a formação de coordenadores de turma e de alfabetizadores. Brasília, abril de 2011. Disponível em:

http://portal.mec.gov.br/index.php?option=com_content\&view=article\&id=17457\&Itemid=8 17. Acesso em: 18 de agosto de 2014.

BRASIL. Ministério do Planejamento, Orçamento e Gestão. Instituto Brasileiro de Geografia e Estatística. Diretoria de Pesquisas - Coordenação de Populações e Indicadores Sociais. Síntese de Indicadores sociais: uma analise das condições de vida da população brasileira. Estudos e Pesquisa, Rio de Janeiro, n. 27, 2010.

BRASIL. Ministério da Educação. Secretaria de Educação Continuada, Alfabetização e Diversidade. Documento Nacional Preparatório à VI Conferência Internacional de Educação de Adultos (VI CONFINTEA), Brasília: MEC; Goiânia: FUNAPE/UFG, 2009.

CALIMAN, Geraldo. Pedagogia social: seu potencial critico e transformador. Revista de Ciências da Educação, UNISAL. Americana/SP. Ano XII, n. ${ }^{\circ} 23$, p. 341-368, $2^{\circ}$ Semestre/2010.

CASTEL, Robert. A dinâmica dos processos de marginalização: da vulnerabilidade à desfiliação. Caderno do CRH. UFBA, Salvador, n. 26-7, p. 19-40, 1997.

CASTEL, Robert. As metamorfoses da questão social: uma crônica do salário. Trad. de Iraci D. Poleti. Petrópolis, RJ: Vozes, 1998.

CASTEL, Robert. As armadilhas da exclusão. In. BELFIOREWANDERLEY, Mariângela; BÓGUS, Lúcia e YAZBEK, Maria Carmelita. Desigualdade e a questão social. São Paulo: EDUC, 2000.

CASTEL, Robert. A discriminação negativa: cidadãos ou autóctones? Trad. Francisco Morás. $2^{\mathrm{a}}$ ed. Petrópolis. RJ: Vozes, 2011.

FRANCISCO, João. Pobreza e exclusão social. Coimbra, Portugal, Faculdade de Economia, Universidade de Coimbra, 2010. Disponível em:

http://www4.fe.uc.pt/fontes/trabalhos/2009012.pdf. Acesso em: 02 de dezembro de 2012.

FILGUEIRAS, Luiz; GONÇALVES, Reinaldo. Desestruturação do trabalho e política social. Disponível em:

http://www.ie.ufrj.br/oldroot/hpp/intranet/pdfs/desestruturacao_do_trabalho_e_politica_social _abril_2009.pdf. Acesso em: 12 de dezembro de 2011.

FREIRE, Paulo. Conscientização: teoria e prática de libertação. São Paulo: Cortez e Moraes, 1979.

FREIRE, Paulo. Pedagogia da esperança: Um reencontro com a pedagogia do oprimido. Rio de Janeiro: Paz e Terra, 1992. 
FREIRE, Paulo; SHOR, Ira. Medo e ousadia: o cotidiano do professor. Trad.: Adriana Lopes. 2 ed. Rio de Janeiro: Paz e Terra, 1986.

GADOTTI, Moacir. Educação Popular, Educação Social, Educação Comunitária: conceitos e práticas diversas, cimentadas por uma causa comum. Revista Diálogos: pesquisa em extensão universitária. IV Congresso Internacional de Pedagogia Social: domínio epistemológico. Brasília, v.18, n.1, p. 10-32 dez, 2012.

GRACIANI, Maria Stela S. A pedagogia social no trabalho com criança e adolescentes em situação de rua. In. SOUZA NETO, João Clemente; SILVA, Roberto da; MOURA, Rogério. Pedagogia Social. São Paulo: Expressão e Arte, 2009. p. 207-224

GRACIANI, Maria Stela S. Pedagogia Social. São Paulo: Cortez, 2014.

HADDAD, Sérgio; DI PIERRO, Maria Clara. Escolarização de jovens e adultos. Revista Brasileira de Educação, n. 14, mai./jun./ago., 2000.

KUENZER, Acácia. Exclusão includente e inclusão excludente: a nova forma de dualidade estrutural que objetiva as novas relações entre educação e trabalho. In: SAVIANI, D.; SANFELICE, J.L.; LOMBARDI, J.C. (Org.).Capitalismo, trabalho e educação. 3. ed. Campinas: Autores Associados, 2005. p. 77-96.

LARROYO, Francisco. História geral da pedagogia. São Paulo: Mestre Jou, 1970.

MACHADO, Evelcy Monteiro. A pedagogia social: reflexões e diálogos necessários. In. SILVA, Roberto da; SOUZA NETO, João C; MOURA, Rogério. Pedagogia social. São Paulo: Expressão e Arte, 2009. pp. 133-148

MARSHALL. T.H. Cidadania, classe social e status. Rio de Janeiro: Zahar editores, 1967.

MÉSZAROS, István. A educação para além do capital. São Paulo: Boi Tempo Editorial, 2005.

PAIVA, Vanilda Pereira. Educação popular e educação de adultos. $5^{\text {a }}$ edição - São Paulo: Edições Loyola, Ibrades, 1987.

PEREIRA, Antonio. A educação de adolescentes em situação de risco social no contexto da pedagogia social e educação de adultos. Anais, I Congresso Internacional de Educação de Jovens e Adultos, Cátedra UNESCO EJA, João Pessoa, Universidade Federal da Paraiba, 20 a 23 de julho de 2010. Disponível em: http://www.catedraunescoeja.org/GT03/COM/COM001.pdf Acesso em: dezembro de 2010.

PEREIRA, Antonio. Currículo e formação de educadores na pedagogia social: relato de uma pesquisa-formação. Revista Profissão Docente, Universidade de Uberaba/UNIUBE, Uberaba, MG, v. 13, n. 29, p. 9-35, jul./dez., 2013. Disponível em: www.revistas.uniube.br/index.php/rpd/article/download/545/731. Acesso em 11 de novembro de 2013.

PEREIRA, Antonio. A educação não formal e educação social na ordem do dia: entre conflitos e possibilidades educativas. Metáfora Educacional. Feira de Santana, Ba, n. 15, p. 
129-148, jul. - dez. 2013. Disponível em:

http://dialnet.unirioja.es/descarga/articulo/4699149.pdf. Acesso em: 15 de janeiro de 2014.

POCHMANN, Márcio. Proteção social na periferia do capitalismo: considerações sobre o Brasil. Revista São Paulo em Perspectiva, São Paulo, v. 18, n. 2, p. 3-16, Abr./jun., 2004.

RIBEIRO, Maria Luisa. História da educação brasileira: a organização Escolar. Campinas: Autores Associados, 1982.

RUMMERT, Sonia Maria; VENTURA, Jaqueline Pereira. Políticas públicas para a educação de jovens e adultos no Brasil: a permanência (re) construção da subalternidade considerações sobre os Programas Brasil Alfabetizado e Fazenda Escola. Revista Educar, Universidade Federal do Paraná, Paraná, n. 29, p. 29-45, 2007.

SANTIAGO, Eliete; BATISTA NETO, José. Formação de professores em Paulo Freire: uma filosofia como jeito ser-estar e fazer pedagógico. Revista E-Currículo, PUC-SP, São Paulo, v. 7, n. 3, p. 1-20, dezembro de 2011.

SAVIANI, Dermeval. Entrevista: A educação fora da escola. Revista de Ciências da Educação. UNISAL, Americana/SP, ano XI, n. ${ }^{\circ}$ 20, p. 17-27, $1^{\circ}$ Semestre/2009.

STRECK, Danilo R.; SANTOS, Karine. Educação de Jovens e Adultos: diálogos com a Pedagogia Social e Educação Popular. EccoS Revista Científica, São Paulo, UNINOVE, n. 25, p. 19-37, Jan./Jun., 2011.

SOUSA, Maria do Socorro Alves. A pobreza como representação: o que faz um agente social ser considerado pobre no Programa Comunidade Solidária. 1999. Dissertação (Mestrado em Política Pública) - Departamento de Políticas Publicas, Universidade Federal do Maranhão, 1999.

UNESCO. Declaração Mundial sobre Educação para Todos. Jomtien, Tailândia, 1990. Disponível em: http://unesdoc.unesco.org/images/0008/000862/086291por.pdf. Acesso em: 04 de janeiro de 2015.

\section{$\underline{\text { SOBRE O AUTOR }}$}

\section{Antonio Pereira}

Doutor em Educação pela Universidade Federal da Bahia (UFBA). Professora do Programa de Pós-Graduação em Educação de Jovens e Adultos, da Universidade do Estado da Bahia (UNEB). E-mail: antonyopereira@yahoo.com.br 